\title{
A CUMULATIVIDADE DOS ADICIONAIS DE PERICULOSIDADE E INSALUBRIDADE COM BASE NO DIREITO VIVO
}

\author{
Vinícius Gozdecki Quirino Barbosa ${ }^{357}$
}

Recebido em: 30/11/2016

Aprovado em: 15/05/2017

\begin{abstract}
RESUMO
A preocupação com a saúde não deve ocorrer apenas pelo Estado, mas também diretamente pelo empregador em uma relação empregatícia. Alguns doutrinadores apenas analisam de forma obscura o pagamento dos adicionais previstos no ordenamento jurídico, contudo, esquecem da forma que se dá a exploração da saúde dos trabalhadores. Será que o princípio da dignidade da pessoa humana é verificado quando o obreiro ao mesmo tempo é exposto a agentes insalubres e perigosos e ainda assim deve optar por perceber apenas um dos adicionais? Tendo em vista que a saúde do trabalhador está em risco ao estar exposto ao agente insalubre e que quando está exposto ao agente perigoso é a integridade física do obreiro que está ameaçada, mesmo assim deve perceber apenas um adicional? Utilizando as lições de Eugen Ehrlich, o que deve ser analisado é a real atividade desempenhada pelo trabalhador no dia a dia, e não apenas o que está na lei.
\end{abstract}

Palavras-chave: Adicional de insalubridade. Adicional de periculosidade. Cumulatividade de adicionais. Direito vivo.

\section{INTRODUÇÃO}

A Constituição Federal traz como um dos principais fundamentos a dignidade da pessoa humana, porém, observa-se que diariamente este princípio é desrespeitado na relação de trabalho, como ocorre, por exemplo, nos locais em que há trabalho em condições análogas às de escravo e assédio sexual.

\footnotetext{
357 Mestrando em Direitos Fundamentais e Democracia pelo Centro Universitário Autônomo do Brasil UNIBRASIL. Pós-Graduado em Direito e Processo do Trabalho e Direito Previdenciário pela Escola da Associação dos Magistrados do Paraná - EMATRA. Bacharel em Direito pelo UNIBRASIL. Advogado.
} 
Impende realçar que a monetização da saúde dos trabalhadores é uma realidade presente no Direito do Trabalho. Infelizmente na sociedade há entendimento de que tudo tem seu preço, até mesmo a saúde do trabalhador.

Os direitos fundamentais do trabalhador são mais importantes que o capital, mas inúmeros empresários agem de maneira equivocada, tendo em vista que no local de labor a saúde dos trabalhadores é colocada em segundo plano, visto que em primeiro lugar o empregador visa ao capital e à produção.

Cada agente gravoso torna prejudicial um bem da vida, pois a insalubridade afeta a saúde e a periculosidade ameaça à integridade física do trabalhador.

O intuito do pagamento dos adicionais é compensar o obreiro em razão dos danos causados, assim, tem-se que nada mais justo que o mesmo perceba de forma cumulada, visto que poderá ter prejuízos à saúde e à vida.

No primeiro capítulo será analisado o princípio da dignidade da pessoa humana. Nos próximos dois capítulos serão abordadas as características, os percentuais de pagamento, as razões de receber, bem como quais trabalhadores fazem jus aos adicionais de periculosidade e insalubridade. Por fim, no último capítulo, serão apresentadas as razões pelas quais o obreiro deve perceber de forma cumulada os adicionais de periculosidade e insalubridade.

\section{PRINCÍPIO DA DIGNIDADE DA PESSOA HUMANA}

O meio ambiente de trabalho adequado não é apenas um direito trabalhista em razão do vínculo de emprego, mas sim um direito fundamental do empregado, visto que deve ser preservada a saúde do obreiro. (MELO, 2010, p. 34).

$\mathrm{O}$ artigo 225 da Constituição Federal trata que "todos têm direito ao meio ambiente ecologicamente equilibrado, bem de uso comum do povo e essencial à sadia qualidade de vida, impondo-se ao Poder Público e à coletividade o dever de defendê-lo e preservá-lo para as presentes e futuras gerações".

O artigo 170 da Constituição Federal garante a valorização do trabalho humano, devendo ser observada a defesa do meio ambiente, que evidentemente abrange o meio ambiente do trabalho.

Com base na DECLARAÇÃO DE ESTOCOLMO (1972), pode-se dizer que o direito ao meio ambiente de trabalho saudável é um direito humano fundamental. Veja-se: 
Princípio I: O homem tem o direito fundamental à liberdade, à igualdade e ao desfrute de condições de vida adequadas, em um meio ambiente de qualidade tal que lhe permita levar uma vida digna, gozar de bem-estar e é portador solene de obrigação de proteger e melhorar o meio ambiente, para as gerações presentes e futuras.

Assim sendo, devem ser observadas as normas concernentes à proteção do meio ambiente, ou seja, preservar a vida do trabalhador, tornando digno e seguro o local de trabalho.

No local de labor a saúde dos trabalhadores é colocada em segundo plano, visto que em primeiro lugar o empregador visa ao capital e à produção. Ou seja, há enorme desrespeito no tocante às normas jurídicas vigentes.

A dignidade da pessoa humana está apontada entre os fundamentos da República Federativa do Brasil, pois está inserida no artigo $1^{\circ}$, III, CF, devendo ser compreendida como fonte do ordenamento jurídico, pois a partir desse fundamento é possível alcançar os demais objetivos, entre eles a erradicação da pobreza e a construção de uma sociedade justa.

Alguns doutrinadores explicam a enorme ligação entre o Direito do Trabalho e a dignidade da pessoa humana. O Direito do Trabalho deve preservar e resguardar a dignidade da pessoa humana do trabalhador.

Vale lembrar que quem detém os meios de produção é o empregador, bem como que ocorrem abusos no âmbito trabalhista. Realce-se que muitos empregadores esquecem que deve haver respeito recíproco, devendo imperar a valorização do ser humano em qualquer ato realizado.

No tocante ao direito à saúde, destaca-se que não se deve considerar apenas a integridade física, mas também a integridade psíquica. Da mesma forma, a preocupação com a saúde não deve ocorrer apenas pelo Estado, aguardando a proteção de modo direto para toda a população, mas sim diretamente pelo empregador, visando à salubridade do meio ambiente laboral, pois em inúmeros locais a saúde é esquecida, em razão de visar apenas ao lucro mensal.

O trabalhador não pode ficar contente e saciado apenas com o direito de poder laborar em determinada empresa, mas deve verificar se as condições de trabalho apresentadas são dignas e pensar primeiramente em sua saúde. Note-se que não há como obter uma excelente qualidade de vida se não há qualidade no ambiente de trabalho.

ROCHA (2002, p. 28) destaca que "a proteção ao meio ambiente de trabalho incorpora a necessidade de busca das causas e medidas preventivas, para que não ocorram efeitos deletéricos para o ser humano (acidente de trabalho e doença ocupacional)."

No mesmo sentido, NASCIMENTO (2009, p. 527-528) trata que: 
A proteção ao meio ambiente do trabalho tem por suporte um conceito: para que o trabalhador atue em local apropriado, o Direito deve fixar condições mínimas a serem observadas pelas empresas, quer quanto às instalações onde as oficinas e demais dependências se situam, quer quanto às condições de contágio com agentes nocivos à saúde ou de perigo que a atividade possa oferecer.

O empregador pode tornar digna a qualidade de vida no ambiente laboral, analisando as ideias dos obreiros, pois são esses que sofrem no dia a dia com os incômodos nos locais inóspitos. Dar valor ao labor é assegurar a importância do obreiro, amparando assim a dignidade humana. OLIVEIRA (2011, p. 107) versa que "percebe-se cada vez mais a valorização do trabalho como atividade dignificante, ou seja, o trabalho não pode ser utilizado como instrumento de subjugação ou de desrespeito à pessoa humana. "

As pessoas almejam melhores empregos com o desígnio de ganhar a vida, porém, observa-se que é o labor que embolsa a vida dos obreiros. Veja-se que muitos trabalhadores abandonam a vida familiar e social com o escopo de aumentar o poder econômico e auferir cada vez mais os famosos bens materiais. E claro, a maior parte dos obreiros dispensa a maior parte do dia para o labor. As empresas devem proporcionar um ambiente agradável aos funcionários, pois são estes que produzem para ampliar o capital do empregador.

No tocante à saúde do obreiro, adianta o trabalhador laborar e perceber um salário considerado favorável, mas prejudicar a saúde tornando-a comprometida?

Deste modo, deve ser feita a seguinte indagação: será que o princípio da dignidade da pessoa humana é verificado quando o obreiro ao mesmo tempo é exposto a agentes insalubres e perigosos e ainda assim deve optar por perceber apenas um dos adicionais?

\section{ADICIONAL DE INSALUBRIDADE}

O conceito de insalubridade está disciplinado no artigo 189 da Consolidação das Leis do Trabalho: "Serão consideradas atividades ou operações insalubres aquelas que, por sua natureza, condições ou métodos de trabalho, exponham os empregados a agentes nocivos à saúde, acima dos limites de tolerância fixados em razão da natureza e da intensidade do agente e do tempo de exposição aos seus efeitos."

A partir do momento em que o obreiro está exposto a agentes insalubres, este passa a ter direito ao percebimento do adicional, assim, nasce o direito a receber um acréscimo salarial, 
devendo ser pago até o momento em que o trabalhador não estiver mais exposto às condições insalubres superiores aos parâmetros de tolerância determinados pelo Ministério do Trabalho.

As atividades insalubres estão estabelecidas na Norma Regulamentadora n. ${ }^{\circ} 15$ da Portaria n. ${ }^{\circ}$ 3.214/78 do Ministério do Trabalho. O artigo 192 da CLT institui que o referido adicional deve ser pago sobre o salário mínimo, nos seguintes percentuais: 10\% (grau mínimo), $20 \%$ (grau médio) e 40\% (grau máximo).

SANTOS (2010, p. 144) trata que se torna benéfico ao empregador o pagamento de percentual baixo:

Porquanto, em tese, o objetivo do pagamento é, em relação ao empregador, forçar que seja promovida a neutralização ou eliminação dos agentes de risco do meio ambiente do trabalho, o adicional de insalubridade e a indenização mencionada devem ser substanciais. Caso contrário haveria inversão e distorção da aplicação do princípio ambiental do poluidor-pagador: ao empresário dar-se-ia carta branca para optar em pagar para expor o trabalhador a risco, sem necessidade de atenção ao princípio da máxima proteção ao ambiente laboral. De certo, valores baixos incentivam o empregador a comprar a saúde do trabalhador. Por isso, os valores têm que ser de certa monta a fim de atrair o empresário, que pensa com o bolso, à promoção da adequação do meio ambiente do trabalho, por ser mais vantajoso no planejamento dos custos do negócio.

Desta forma, é notório que o pagamento do adicional de insalubridade sobre o salário mínimo torna-se vantajoso para o empregador. Saliente-se que não há um grande impacto econômico, visto que o empresário promete determinado salário, contudo, nessa promessa já está incluso o valor do percentual do adicional devido.

Nesse sentido, CESÁRIO (2012, p. 74) explica que:

Como se não bastasse, as táticas de diluição contábil dos salários em adicionais são extremamente simples e eficazes para a extração da mais-valia. Se, por exemplo, um empregador for contratado para auferir o salário mensal de $\mathrm{R} \$ 654,00$ (seiscentos e cinquenta e quatro reais), para trabalhar em um ambiente insalubre de grau médio, será muito simples para o empregador contabilizar no recibo de pagamento o mínimo de $\mathrm{R} \$ 545,00$ (quinhentos e quarenta e cinco reais) pagos a título de salário de sentido estrito, mais o montante de $\mathrm{R} \$ 109,00$ (cento e nove reais) pretensamente adimplidos como o adicional de $20 \%$ da insalubridade.Tudo dentro da lei! Mas a rigor, o trabalhador nada receberá para esvair sua saúde em um ambiente insalubre.

Para o empresário é menos oneroso pagar o adicional sobre o salário mínimo do que investir no ambiente laboral com o intuito de torná-lo saudável. Pode-se dizer, assim, que o obreiro está vendendo a sua saúde em troca do trabalho. 
A Súmula n. ${ }^{\circ} 448$, I, do Tribunal Superior do Trabalho, versa que o empregador deve pagar o adicional de insalubridade apenas se a atividade estiver enquadrada na relação oficial elaborada pelo Ministério do Trabalho.

Desta forma, resta claro e evidente que determinados empregadores são beneficiados pela súmula supramencionada, visto que se o obreiro laborar em local insalubre e a atividade desenvolvida não estiver na relação do Ministério do Trabalho, este será o único prejudicado em razão da atividade desenvolvida. Ademais, o empregado só irá obter o direito de perceber o adicional se forem cumulados dois requisitos: I) exposição a agentes nocivos à saúde e II) essa exposição deve ser superior ao limite estabelecido pelo referido Ministério do Trabalho.

GONÇALVES (2003, p. 30) explica que:

\begin{abstract}
Culturalmente, tem predominado a ideia de que proteger o trabalhador significa fornecer-lhe equipamento de proteção individual, entretanto, não se pode perder de vista o fato de que, a rigor, o EPI não previne a ocorrência de acidentes do trabalho, mas apenas evita ou atenua a gravidade das lesões, daí por que há de se procurar, sempre e em primeiro lugar, a proteção coletiva, dada a sua melhor eficácia, uma vez que elimina ou neutraliza o risco ambiental na sua fonte produtora, além do que essa modalidade preventiva não fica à mercê da utilização ou não por parte do empregado.
\end{abstract}

Contudo, impende realçar que a Súmula n. ${ }^{\circ} 289$ do Tribunal Superior do Trabalho versa que o mero fornecimento do equipamento de proteção individual não retira a obrigatoriedade de o empregador pagar o adicional de insalubridade. Já a Súmula n. ${ }^{\circ} 80$ do TST aborda que se advir a eliminação da insalubridade, o obreiro perderá o direito ao percebimento. Ou seja, o empregador deve comprovar que o aparelho era utilizado de forma correta e que o risco foi eliminado, assim, poderá eximir-se do pagamento.

Infelizmente muitos trabalhadores preferem trabalhar em locais insalubres, visto que irão receber um plus salarial. No entanto, esquecem dos riscos à saúde. Ou seja, vendem a saúde por um preço ínfimo ao invés de buscarem melhores condições de trabalho. Além disso, muitos até pensam em uma futura reclamatória trabalhista, em razão de que irão receber o adicional de insalubridade dos últimos 5 anos com os devidos juros. (MELO, 2010, p. 34).

\title{
4 ADICIONAL DE PERICULOSIDADE
}

O artigo 189 da CLT trata que "são consideradas atividades ou operações perigosas, na forma da regulamentação aprovada pelo Ministério do Trabalho, aquelas que, por sua natureza 
ou métodos de trabalho, impliquem o contato permanente com inflamáveis ou explosivos em condições de risco acentuado."

O artigo 193 da CLT determinava o pagamento do adicional de periculosidade quando o obreiro tivesse contato permanente. Contudo, a Lei n. ${ }^{\circ}$ 12.740/2012 alterou a redação, deste modo, a palavra contato foi substituída por exposição.

A expressão contato é mais restrita do que exposição, pois a primeira traduz a ideia de o obreiro estar próximo ao risco, já a segunda facilitou o percebimento do adicional de periculosidade, em razão de o trabalhador não necessitar do contato direto com as atividades periculosas, mas tão somente estar exposto ao risco.

A periculosidade está associada ao risco de vida, visto que pode acontecer acidente em todo o período em que o obreiro está laborando. Destaca-se que não há necessidade de o trabalhador estar exposto ao risco durante todo o horário de labor diário, basta apenas a exposição de forma intermitente, assim, já faz jus ao adicional de periculosidade, desde que seja habitual. A Súmula n. ${ }^{\text {o }} 364$ do Tribunal Superior do Trabalho trata que caso ocorra de forma eventual ou por tempo extremamente mínimo, não há pagamento do adicional de periculosidade.

MIRANDA (2012, p. 1) ensina que:

Diferentemente do adicional de insalubridade, que afeta a saúde do trabalhador, o adicional de periculosidade, tem o objetivo de 'compensar' o empregado que desenvolve sua atividade em risco eminente de sua vida. Deve-se considerar que um trabalhador desenvolve uma atividade perigosa quando esta causa risco a sua vida ou a sua incolumidade física.

Note-se que não deve ser considerado o tempo de exposição do empregado, mas sim o risco a que este está exposto. A partir do momento em que o obreiro não estiver mais exposto ao risco, cessa o pagamento do referido adicional, assim, não gera direito adquirido.

O artigo 195 da CLT estabelece que para que seja determinado o pagamento do adicional de periculosidade, assim como o de insalubridade, deve ser determinada perícia. Contudo, há casos em que não há necessidade de ser realizada perícia para que seja deferido o adicional, como é o caso dos obreiros que operam em bomba de gasolina, conforme trata a Súmula n. 39 do TST: "Os empregados que operam em bomba de gasolina têm direito ao adicional de periculosidade." Da mesma forma, os bombeiros profissionais têm direito ao adicional, sendo desnecessária a perícia, conforme trata o artigo 6º III, da Lei n. ${ }^{\circ}$ 11.901/2009.

Ademais, se a empresa pagar o adicional de periculosidade por mera liberalidade, não há necessidade de realizar a perícia, ainda que pago proporcionalmente ao tempo exposto ao 
risco ou o percentual for abaixo do determinado, visto que se torna incontroversa a periculosidade, conforme determina a Súmula n. ${ }^{\circ} 453$ do TST.

Impende realçar que não há como eliminar a periculosidade somente com o fornecimento dos equipamentos de proteção individual, pois o adicional apenas compensa o risco. MARTINS (2012, p. 265) versa que "para o adicional de periculosidade não ser devido, mister se faz que o risco seja eliminado e não neutralizado, porque a qualquer momento o trabalhador pode ser surpreendido com uma descarga elétrica, em que tal risco continua logicamente a existir. "Assim, para que o pagamento seja suprimido pelo empregador, deve ocorrer a eliminação do risco (ex: alteração do local de trabalho do obreiro).

\title{
5 A CUMULATIVIDADE DOS ADICIONAIS DE PERICULOSIDAdE E INSALUBRIDADE
}

Primeiramente, deve ser abordado que o Direito do trabalho legaliza o trabalho degradante, sendo que a partir deste o obreiro percebe apenas uma remuneração superior em razão do trabalho realizado, porém, a mesma não compensa a totalidade dos riscos a que os obreiros estão expostos. Mais, é notável que a legislação não demonstra a devida preocupação com a eliminação dos riscos. Ou seja, não há a figura do bem-estar ao trabalhador, tendo em vista que sempre estará exposto aos agentes prejudiciais à saúde.

Nesse sentido, RAMOS FILHO (2010, p. 400) ensina que:

\begin{abstract}
O Direito Capitalista do Trabalho vigente no Brasil, em sua ambivalência, na exata medida em que garante aos trabalhadores o direito à percepção de adicionais por trabalho prestado em condições de risco à saúde (insalubridade) ou à vida (periculosidade), assegura aos empregadores o direito de exigir trabalho degradante de empregados desde que pague por isso, ou seja, desde que pague corretamente os adicionais estabelecidos por lei para o trabalho em tais condições de risco. Dito de outro modo: se o empregador paga o adicional previsto na legislação (seja o de insalubridade, seja o de periculosidade), o trabalho continua a ser degradante, mas as regras positivas do Direito Capitalista do Trabalho terão sido cumpridas. De outra parte, se o empregador deixa de aproveitar a faculdade que a ambivalente legislação trabalhista lhe assegura (exigir trabalho degradante, pagando algo mais ao obreiro degradado), se está diante de uma conduta tipificada como crime, qual seja, a de submeter empregado a 'condições degradante de trabalho.
\end{abstract}

A relação laboral é encarada como uma relação de poder, tendo em vista que o empregador possui o poder denominado diretivo, sendo aplicado sobre os obreiros. Vale 
ressaltar que inúmeros empresários esquecem que antes de ser empregado, o trabalhador deve ser visto como ser humano, devendo ser tratado de forma digna.

Os próprios empresários sofrem com os prejuízos, pois com o adoecimento dos obreiros o trabalho tende a atrasar. Além disso, esquecem de analisar os gastos que terão com os referidos adoecimentos.

CESÁRIO (2012, p. 72) ensina que:

[...] o fato é que os juslaboralistas continuam conservadoramente imbuídos do propósito de tão-somente reconhecer aos trabalhadores os tradicionais adicionais econômicos que tanto caracterizam - às vezes até pejorativamente - esse ramo do conhecimento jurídico especializado, descurando-se, por completo, da responsabilidade que possuem em concretizar a promessa constitucional de redução dos riscos inerentes ao trabalho.

Os trabalhadores devem analisar que o percebimento do adicional não deve ser tratado como um benefício, tendo em vista os malefícios ocasionados em razão da exposição.

COSTA (2013, p. 131) alega que:

Existe, na mentalidade de muitos, uma distorção valorativa do direito à percepção do adicional pelo trabalhador, que deixa de reivindicar melhores condições e se recusa a laborar em outro ambiente salubre, diante da perda dos supostos benefícios decorrentes do aumento salarial e da aposentadoria precoce.

No tocante à saúde do obreiro no ambiente laboral há entendimento de alguns doutrinadores que ainda que o trabalhador esteja exposto a agentes insalubres e perigosos, mesmo assim deve optar por um adicional, em razão do texto do artigo 193 da CLT.

Contudo, veja-se que se o obreiro laborar em período noturno e em sobrejornada, obviamente deverá perceber o adicional de horas extras, bem como o adicional noturno. Desta forma, então, por qual razão o obreiro não deve perceber os adicionais de insalubridade e periculosidade se ao mesmo tempo estiver exposto às condições insalubres e periculosas?

Assim consta do INFORMATIVO N. 134 DO TST (Período: 26 de abril a 2 de maio de 2016):

Adicional de insalubridade e de periculosidade. Cumulação. Impossibilidade. Prevalência do art. 193, § $2^{\circ}$, da CLT ante as Convenções no ${ }^{\circ} 148$ e 155 da OIT. É vedada a percepção cumulativa dos adicionais de insalubridade e de periculosidade ante a expressa dicção do art. 193, § $2^{\circ}$, da CLT. Ademais, não obstante as Convenções $\mathrm{n}^{\circ} \mathrm{s} 148$ e 155 da Organização Internacional do Trabalho (OIT) tenham sido incorporadas ao ordenamento jurídico brasileiro, elas não se sobrepõem à norma interna que consagra entendimento diametralmente oposto, aplicando-se tão somente às situações ainda não reguladas por lei. Sob esse fundamento, a SBDI-I, por unanimidade, conheceu do recurso de embargos, por divergência jurisprudencial, e no mérito, por maioria, negou-lhe provimento. Vencidos os Ministros Cláudio Mascarenhas Brandão, relator, Augusto César de Carvalho, Hugo Carlos 
Scheuermann e Alexandre Agra Belmonte. TSTE-ARR-1081-60.2012.5.03.0064, SBDI-I, rel. Min. Cláudio Mascarenhas Brandão, red. p/ acórdão Min. João Oreste Dalazen, 28.4.2016.

De início deve ser observado que ainda que haja lei que trate que os adicionais não devem ser cumulados (o que não é o caso), destaca-se que no Direito do Trabalho há o princípio da realidade sobre a forma. O referido princípio aborda que o que realmente vale é o que acontece na prática, ou seja, no dia a dia do trabalhador. Os fatos imperam sobre o contrato. $\mathrm{O}$ direito vivo, segundo Ehrlich, não está somente em leis ou jurisprudências, mas sim na vida como um todo. O direito vivo domina a vida.

O texto do enunciado supramencionado abrange somente a lei, ou seja, não analisa o que Ehrlich trata de direito vivo, pois em nenhum momento versa sobre o que realmente acontece na prática.

Segundo MALISKA (2015, p. 123), o que deve ser aplicado nesse caso é o que Ehrlich trata como direito vivo:

Ainda que o documento jurídico seja uma fonte importante para a investigação do
direito vivo, não se pode supervalorizá-lo imaginando que todo o seu conteúdo seja
portador e um testemunho do direito vivo. Direito vivo no conteúdo de um documento
é aquilo que as partes, na vida real, de fato, observam e não o que os tribunais declaram
como obrigatório para o caso.

Analisando o dia a dia dos trabalhadores, tendo em vista que em determinadas atividades os obreiros estão expostos a agentes insalubres e perigosos ao longo da atividade diária, qual a razão para não cumular os adicionais?

Os adicionais de periculosidade e insalubridade não se confundem, visto que são parcelas distintas e os fatos geradores são diversos. O adicional de insalubridade compensa os danos à saúde do trabalhador, já o adicional de periculosidade tem o intuito de compensar os riscos à vida (os quais não são eliminados através do fornecimento de equipamentos de proteção individual), ainda que o obreiro esteja exposto por pouco tempo.

Nesse sentido, VENDRAME $(1997$, p. 28) aborda que:

Não existe qualquer relação de semelhança entre os adicionais de insalubridade e periculosidade, cada um remunerando uma situação distinta de exposição do trabalhador. Enquanto o adicional de insalubridade responde pelos danos à saúde do trabalhador, geralmente provocados por doenças do trabalho ou profissionais, o adicional de periculosidade remunera o risco de acidentes; aquele compreende o agente que age de forma insidiosa e contínua, este, ao contrário, é o infortúnio, o segundo que pode ceifar a vida do trabalhador.

FORMOLO (2006, p. 55) destaca que: 


\begin{abstract}
No caso, de se optar pelo adicional de periculosidade, estará trabalhando em condições insalubres 'de graça', ou seja, sem nenhuma compensação pecuniária, e vice versa no caso de optar pelo adicional de insalubridade (caso em que o labor em condições perigosas será prestado sem nenhuma compensação pecuniária), ao arrepio da constituição e sujeitando-se a manifesto desequilíbrio e desvantagens na relação contratual, comprometida que fica, em rigor, a equivalência das prestações dos sujeitos contratantes.
\end{abstract}

Se o intuito do pagamento dos adicionais é compensar o obreiro em razão dos danos causados, tem-se que nada mais justo que o mesmo perceba de forma cumulada, visto que poderá ter prejuízos à saúde e à vida.

Conforme MALISKA (2015, p.126-127), Ehrlich ensina que:

\begin{abstract}
A investigação orienta-se em normas que dominam, de fato, a prática jurídica, em uma ordem jurídica em que de fato se vive. Uma segunda perspectiva demonstra que a investigação do direito vivo compreende as normas que efetivamente possuem eficácia na relação social entre as pessoas. Uma ciência jurídica útil não pode apenas se reduzir ao direito escrito, mas deve também dar atenção ao que de fato ocorre na prática jurídica.
\end{abstract}

Os tratados internacionais que versam sobre a proteção dos obreiros são admitidos no ordenamento nacional a fim de ampliar os direitos já aceitos, conforme elencados no artigo $7^{\circ}$ da Constituição Federal. Os tratados têm o valor hierárquico destinado às leis federais, ou seja, são enquadrados com hierarquias constitucionais.

Contudo, sendo que há controvérsia em grande parte dos temas relacionados ao direito, há doutrinadores que compreendem que a Constituição Federal possui supremacia em relação aos tratados internacionais, assim, entendem que os tratados de direitos humanos são infraconstitucionais. Já os adeptos da ideia contrária versam que há superioridade se comparar o direito internacional com o direito nacional.

Ademais, destaca-se que os tratados de direitos humanos possuem alicerce na norma mais favorável, em razão do princípio da dignidade da pessoa humana.

Ressalte-se que ainda que muitos entendam que o artigo 193, § 2, da CLT seja recepcionado pela $\mathrm{CF}$, deve prevalecer o entendimento de que o mesmo foi revogado pela Convenção n. ${ }^{\circ} 155$ da OIT.

Além disso, impende realçar que os parágrafos $1^{\circ}$ e $2^{\circ}$, do artigo $5^{\circ}, \mathrm{CF}$, determinam a hierarquia de norma constitucional aos direitos elencados em tratados de cunho internacional.

O Brasil ratificou alguns tratados internacionais após 1988, merecendo destaque a Convenção n. ${ }^{\circ} 148$ da OIT que trata da proteção dos trabalhadores contra os riscos devidos à contaminação do ar, ao ruído e às vibrações no local de trabalho, bem como a Convenção n. ${ }^{\circ}$ 
155 da OIT, a qual trata da segurança e saúde dos trabalhadores e meio ambiente de trabalho. As regras contidas nas aludidas Convenções são superiores as da CLT, visto que deve ser tratada como norma de caráter especial, bem como que a sua incorporação ocorreu após a referida CLT. Impende realçar que a Emenda Constitucional n. ${ }^{\circ}$ 45/2004 inseriu na Constituição Federal o $\S 3^{\circ}$ em seu artigo $5^{\circ}$, estabelecendo que "Os tratados e convenções internacionais sobre direitos humanos que forem aprovados, em cada Casa do Congresso Nacional, em dois turnos, por três quintos dos votos dos respectivos membros, serão equivalentes às emendas constitucionais."

O artigo $4^{\circ}$ da Convenção n. ${ }^{\circ} 155$ da OIT trata que:

Todo Membro deverá, mediante consulta com as organizações mais representativas de empregadores e de trabalhadores interessadas e tendo em conta as condições e prática nacionais, formular, pôr em prática e reexaminar periodicamente uma política nacional coerente em matéria de segurança e saúde dos trabalhadores e meio ambiente de trabalho.

Esta política terá por objetivo prevenir os acidentes e os danos para a saúde que sejam conseqüência do trabalho, guardem relação com a atividade de trabalho ou sobrevenham durante o trabalho, reduzindo ao mínimo, na medida em que seja razoável e factível, as causas dos riscos inerentes ao meio ambiente de trabalho.

O artigo 11, b, da Convenção n. ${ }^{0} 155$ da trata que: "para efeitos de danos à saúde do trabalhador, devem ser considerados, simultaneamente, os vários agentes e substâncias nocivas ao organismo humano."

Veja-se que a aludida Convenção não tem como intuito apenas remunerar melhor o trabalhador, mas sim fazer com que o empregador reduza os níveis prejudiciais à vida do obreiro.

Insta salientar que não deve haver discussão em relação ao princípio da norma mais favorável no direito do trabalho, visto que deve ser aplicado quando for evidenciado o conflito entre normas. No tocante à convenção internacional, não há dúvida de que essa beneficia mais o obreiro, logo, deve prevalecer e imperar em relação ao artigo 193 da CLT.

$\operatorname{KROST}(2004$, p. 220) aborda que:

A regra geral é que o trabalhador receba cumulativamente os adicionais, para compensar separadamente cada condição adversa. Assim, se o empregado trabalhar à noite em sobrejornada receberá o adicional das horas extras juntamente com o adicional noturno; se for transferido e trabalhar em local perigoso receberá cumulativamente os adicionais de transferência e de periculosidade etc.

No entanto, se o trabalhador estiver exposto, simultaneamente, a mais de um agente insalubre, receberá o adicional de insalubridade apenas de um deles, isso porque a NR-15 item 3 da Portaria 3.214/78 vedou a percepção cumulativa, determinando que seja considerado somente o agente de grau mais elevado. 
Além dos fatores já expostos, tem-se ainda o critério cronológico, conforme trata o artigo $2^{\circ}, \S 1^{\circ}$, LICC. No tocante a esse critério, ressalte-se que o Decreto-Lei n. ${ }^{\circ} 1.254 / 94$ que ratificou a Convenção n. ${ }^{\circ} 155$ da OIT é posterior ao Decreto-Lei n. ${ }^{\circ}$ 5.452/43 (CLT), bem como a Lei n. ${ }^{\circ}$ 6.514/77 que instituiu o art. 193 e seus parágrafos. Portanto, a Convenção deve imperar sobre a CLT.

OLIVEIRA (2011, p. 287) defende que o $§ 2^{\circ}$ do artigo 193 da CLT deve ser revogado:

Discute-se, também, a possibilidade de cumulação do adicional de insalubridade com o de periculosidade. Pelas mesmas razões expostas, somos também favoráveis. Aponta-se, como obstáculo à soma dos dois adicionais, a previsão contida do art.193, $\underline{\S 2^{\circ}}$, da CLT: 'O empregado poderá optar pelo adicional de insalubridade que porventura lhe seja devido’. O dispositivo legal indica que os dois adicionais são incompatíveis, podendo o empregado optar por aquele que lhe for mais favorável. Entretanto, após a ratificação e vigência nacional da Convenção $\mathrm{n}^{\circ} 155$ da OIT, esse parágrafo foi revogado, diante da determinação de que sejam considerados os riscos para a saúde decorrentes da exposição simultânea a diversas substâncias ou agentes (art. 11, b).

No tocante à revogação, veja-se que o $\S 2^{\circ}$ do art. $5^{\circ}$ da Constituição Federal trata que "os direitos e garantias expressos nesta Constituição não excluem outros decorrentes do regime e dos princípios por ela adotados, ou dos tratados internacionais em que a República Federativa do Brasil seja parte."

Veja-se que não trata de uma revogação expressa, mas sim tácita, visto que quem admite a cumulação são as Convenções (148 e 155 da OIT) e não a CLT.

Não há dúvidas de que o texto da Convenção n. ${ }^{\circ} 155$ da OIT é mais favorável, em razão de permitir o pagamento de mais de um adicional desde que o trabalhador esteja exposto a mais de um agente.

SOUTO MAIOR (2005, p. 25) diz que:

Acumulação de adicionais: como o princípio é o da proteção do ser humano, consubstanciado, por exemplo, na diminuição dos riscos inerentes ao trabalho, não há o menor sentido continuar-se dizendo que o pagamento de um adicional 'quita' a obrigação quanto ao pagamento de outro adicional. Se um trabalhador trabalha em condição insalubre, por exemplo, ruído, a obrigação do empregador de pagar o respectivo adicional de insalubridade não se elimina pelo fato de já ter este mesmo empregador pago ao empregado adicional de periculosidade pelo risco de vida a que o impôs. Da mesma forma, o pagamento pelo dano à saúde, por exemplo, perda auditiva, nada tem a ver com o dano provocado, por exemplo, pela radiação. Em suma, para cada elemento insalubre é devido um adicional, que, por óbvio, acumula-se com o adicional de periculosidade, eventualmente devido. Assim, dispõe, aliás, a Convenção $\mathrm{n}^{\circ} 155$, da OIT, ratificada pelo Brasil.

O pagamento dos adicionais não deve ser encarado apenas como uma forma de remunerar melhor o trabalhador em razão da exposição aos agentes, mas sim como um modo 
do empregador diminuir os riscos. Ou seja, não cumular o pagamento dos adicionais faz com que o empregador não objetive eliminar os riscos, bem como os agentes nocivos. Desta forma, incitar o empregador a pagar de forma cumulada, faz com que melhore o ambiente laboral, tornando-o propício ao labor.

A ideia da monetização faz pensar que a saúde possui um preço, visto que o obreiro percebe um adicional. No tocante à referida monetização de riscos, OLIVEIRA (2011, p. 138139) ensina que:

\begin{abstract}
Observa-se um movimento permanente de instituir recompensas pelos riscos, o que desvia a preocupação com o problema central, que é a saúde do trabalhador. Foram criados mecanismos para conviver com o mal e não para cortá-lo pela raiz [...]. De fato, a justificativa para o pagamento do adicional pelo trabalho em condições adversas não resiste a cinco minutos de reflexão séria. O adicional - não há como deixar de perceber - significa venda da saúde ou de parte da própria vida, daí o rótulo que vem recebendo de adicional do suicídio ou da morte.
\end{abstract}

Insta salientar que o artigo 193 da CLT não proíbe a cumulatividade dos adicionais, mas tão somente trata que se deve optar por apenas um. Logo, se houver dúvida no tocante as normas, destaca-se que deve ser aplicada a que for mais favorável ao trabalhador, isto é, cumular o percebimento dos adicionais.

GARCIA (2005, p. 741) aborda que:

[...] tende a prevalecer que ele [empregado] não faz jus ao recebimento de ambos os adicionais ao mesmo tempo, entendimento este que, no entanto, merece fundada crítica, pois, se o empregado está exposto tanto a agente insalubre como também à periculosidade, nada mais justo e coerente do que receber ambos os adicionais (art. $7^{\circ}$, inciso XXIII, da CF/88), uma vez que os fatos geradores são distintos e autônomos.

Tendo em vista que a Constituição Federal é a norma de maior hierarquia, tem-se que as demais normas devem ser compatibilizadas com as constitucionais. Logo, a norma trabalhista deve ser compatível com a Constituição Federal, ou seja, devem tornar-se válidos os direitos constitucionais do trabalhador. Deste modo, o fato de não cumular os adicionais de periculosidade e insalubridade só pode prevalecer se for compatível com o texto constitucional. Contudo, encontra-se óbice, visto que há incompatibilidade do $§ 2^{\circ}$ do art. 193 da CLT com a Constituição Federal.

Merece destaque o artigo $7^{\circ}, \mathrm{XXI}, \mathrm{CF}$, visto que trata da "redução dos riscos inerentes ao trabalho". Desta forma, sempre que não forem cumulados os referidos adicionais, ocorre violação as garantias constitucionais.

Nesse aspecto, oportuna é a lição de KROST (2004, p. 220): 
Não há razão biológica, nem lógica e muito menos jurídica para tal vedação. Em termos biológicos, está comprovado que a exposição simultânea a mais de um agente agressivo reduz a resistência do trabalhador, agravando-se ainda mais a situação pelo efeito sinérgico das agressões, isto é, a presença de mais de um agente insalubre além de somar, em muitas circunstâncias, multiplica os danos à saúde.

$[\ldots]$

Também não é lógico nem razoável conferir apenas um adicional na exposição simultânea, fugindo da regra básica de atribuir reparação distinta para cada dano. Um trabalhador, por exemplo, exposto a excesso de ruído (com prejuízo para a audição) e à poeira de sílica (que afeta o sistema respiratório) só recebe o adicional por uma das agressões. Esta regra, aliás, desestimula o empresário a melhorar o ambiente de trabalho, porque tendo um agente insalubre, poderá ter dois, três ou vários outros que o desembolso será sempre o mesmo.

Pelo enfoque jurídico, observa-se que o item 15.3 da NR-15 mencionada não tem validade porque extrapola os limites da lei instituidora da vantagem. Não pode uma simples portaria, ato administrativo que é, limitar o alcance da fonte normativa primária da vantagem, no caso os arts. 189 e 192 da CLT. Se a lei não vedou a percepção cumulativa em decorrência da exposição simultânea que prejudica órgãos distintos do trabalhador, não pode a portaria restringir a abrangência da norma.

Nesse mesmo sentido, RODRIGUES PINTO (2000, p. 334) alega que:

[...] causa profunda espécie que o art. $193, \S 2^{\circ}$, da CLT, herdando restrição levantada desde a Lei n. 2.573/55, que instituiu o adicional de periculosidade, tenha aberto ao empregado submetido às duas condições mais severas de serviço, simultaneamente, $o$ direito de 'optar(?) pelo adicional de insalubridade que porventura lhe seja devido', quando comprovado pericialmente que também trabalhou em condição perigosa. Explicação jurídica não encontramos para isso daí entendermos ter havido uma recaída do legislador em favor do poder econômico.

O fato de não cumular os adicionais de periculosidade e insalubridade não foi recebido pela $\mathrm{CF}$, visto que o artigo $7^{\circ}$ não restringe o pagamento de ambos. Veja-se que há um inciso que garante "a redução dos riscos inerentes ao trabalho" (art. $7^{\circ}, \mathrm{XXII}, \mathrm{CF}$ ) e outro que assegura o "adicional de remuneração para as atividades penosas, insalubres ou perigosas" (art. $7^{\circ}, \mathrm{XXII}$, $\mathrm{CF}$ ), assim, não é possível acolher a ideia de que uma norma infraconstitucional limite a cumulação dos referidos adicionais. FORMOLO E SILVA (2008) alegam que:

A autorização, expressa ou tácita, concedida pela Constituição para a lei estabelecer restrições a direitos fundamentais não é de caráter amplo e ilimitado. Do contrário, correr-se-ia o risco de a legislação ordinária mutilar os direitos assegurados na Constituição [...] A indagação que então se insinua é a seguinte: o teor do $\S 2^{\circ}$ do art. 193 da CLT preserva o conteúdo essencial do inciso XXIII do art. $7^{\circ}$ da Constituição, harmonizando-se com os fins desejados pelo legislador constituinte? A resposta, a nosso ver, é negativa, pois o adicional de insalubridade não se confunde com o de periculosidade, e vice-versa, bem assim os fatos geradores de um e outro também não se confundem entre si.

É notório que se for determinado que há tanto insalubridade quanto periculosidade no local de trabalho, significa que existe perigo à integridade física do obreiro, bem como prejuízo à saúde do mesmo.

Segundo MALISKA (2015, p. 122), Ehrlich ensina que: 
[...] a investigação do direito vivo não pode ficar restrita ao estudo das decisões judiciais, pois elas não fornecem, de fato, um quadro completo da vida jurídica. Apenas uma parte mínima do que ocorre na realidade é levada aos tribunais. Assim, o método sociológico exige que os resultados obtidos a partir das decisões judiciais dos órgãos estatais sejam completados pela observação direta da realidade.

Ainda que a lei seja interpretada de modo contrário, não deve ser analisada tão somente a referida lei, mas sim o que acontece no dia a dia dos trabalhadores, os quais buscam diariamente o lucro para a empresa.

Conforme MALISKA (2015, p. 15), Ehrlich aborda que:

o direito vivo encontra-se na dinâmica da vida, nos desafios que traz o desenvolvimento tecnológico, nas novas práticas sociais; o direito vivo são as regras vinculantes que as pessoas voluntariamente observam na convivência social; em contraposição ao direito vigente perante os tribunais e órgãos estatais, o direito vivo domina a vida. As fontes para conhecê-lo, são sobretudo, os documentos modernos, bem como a observação do dia a dia do comércio, dos costumes e usos e também das associações.

Veja-se que o pagamento de forma cumulada dos referidos adicionais não gera bis in idem, tendo em vista que não há um pagamento duplo sobre o mesmo fato.

De forma clara, ÁGUEDA MARIA LAVORATO PEREIRA (BRASIL, Tribunal Regional do Trabalho da $12^{\mathrm{a}}$ Região, 2013) apresentou os fatores que determinam a percepção dos adicionais de forma cumulada:

\begin{abstract}
Assim sendo, vários motivos admitem a possibilidade de cumulação do pagamento do adicional de insalubridade e do adicional de periculosidade: 1) a previsão contida no $\S 2^{\circ}$ do art. 193 da CLT consiste numa faculdade conferida ao trabalhador submetido aos agentes nocivos e perigosos à sua saúde, quanto ao recebimento do adicional de insalubridade, e não numa obrigação; 2) o adicional de periculosidade tem finalidade e natureza jurídica diversa da do adicional de insalubridade. Enquanto este remunera os males causados à saúde do trabalhador ocasionados pelo contato com agentes agressivos, aquele decorre da mera exposição ao risco (perigo) potencial da ocorrência de acidente; 3) o pagamento de um adicional não 'quita' o do outro; 4) ambas as situações de exposição ao risco e às condições de insalubridade geram efeitos malévolos à saúde do trabalhador; 5) a norma da OIT (Convenção $n^{\circ} 155$ ) faz expressa menção à consideração de ambas as situações (simultâneas) no que diz respeito à proteção da saúde do trabalhador; 6) a possibilidade do recebimento cumulado de tantos adicionais quantos forem os agentes a que estiver exposto favorece o surgimento de meios que estimulem o empregador à melhoria das condições do meio ambiente do trabalho a que está sujeito o trabalhador, fato que inclusive favorece a redução dos custos para a empresa; 7) o recebimento acumulado desses adicionais impossibilita o locupletamento ilícito do empregador pela sonegação dos direitos devidos ao trabalhador que lhe põe à disposição a sua força de trabalho.
\end{abstract}

Segue, ainda, o entendimento atual apresentado pelo MINISTRO RELATOR DOUGLAS ALENCAR RODRIGUES (BRASIL, Tribunal Superior do Trabalho, $7^{\text {a }}$ Turma, 2016) da $7^{\mathrm{a}}$ Turma do Colendo Tribunal Superior do Trabalho publicado em 26-08-2016: 
4. CUMULAÇÃO DOS ADICIONAIS DE INSALUBRIDADE E DE PERICULOSIDADE DECORRENTES DE FATOS GERADORES DISTINTOS. POSSIBILIDADE. O TRT manteve a condenação ao pagamento simultâneo do adicional de periculosidade e do adicional de insalubridade. Ao adotar os fundamentos da sentença, baseados na Convenção no 155 da OIT, a Corte Regional entendeu que a vedação disposta no artigo $193, \S 2^{\circ}$ da CLT não deveria prevalecer na hipótese dos autos. Tem-se que a SBDI-1 do TST, (sessão do dia 28/4/2016, da SBDI-1, E-ARR1081-60.2012.5.03.0064) ao analisar o mesmo tema, firmou entendimento quanto à impossibilidade de cumulação dos adicionais de insalubridade e periculosidade. Concluiu que, nessas situações, tão somente remanesce a opção do empregado pelo adicional que lhe for mais benéfico. Não obstante, ponderou que a vedação de cumulatividade do adicional de insalubridade com o adicional de periculosidade, disposta pelo artigo $193, \S 2^{\circ}$ da CLT, não se revela absoluta. Invocou a necessidade de uma interpretação teleológica e conforme a Constituição Federal, para concluir que mencionada vedação justifica-se apenas nas hipóteses em que os adicionais decorrem da mesma causa de pedir. Entende, assim, a SBDI-1 do TST que restando comprovada a existência de dois fatos geradores distintos, específicos para cada um dos adicionais, deve ser reconhecido o direito à sua percepção de forma cumulativa. No caso dos autos, segundo o quadro fático expressamente delimitado pelo Tribunal Regional, restou comprovado o fato de que cada um dos adicionais tem origem em condicionantes diversas. Primeiramente, foi consignado que "as atividades do autor foram consideradas como periculosas em face da exposição à radiação não ionizante (marcador 15, pág. 15)" (fl. 329) e também que conforme laudo pericial "as atividades desenvolvidas pelo autor são enquadradas como insalubres, em grau médio, por contato e manipulação de produtos químicos - fumos metálicos e ruído" (fl. 331). Por estas razões, o TRT concluiu que "as atividades do autor, além de periculosas, são insalubres" (fl. 331). Nesse cenário, em atendimento à jurisprudência da SBDI-1 do TST, uma vez comprovados nos autos os distintos fatos geradores dos adicionais de periculosidade e insalubridade, deve ser reconhecido o direito à sua cumulação, mediante a interpretação do artigo 193, §2 , da CLT conforme o artigo $7^{\circ}$, XXIII da Constituição Federal.

Veja-se que ser contra a cumulação é desprezar os princípios fundamentais da Constituição Federal, bem como as regras das Convenções Internacionais da Organização Internacional do Trabalho.

Impende realçar que os direitos fundamentais do trabalhador são mais importantes que o valor econômico, porém, na maioria dos casos, infelizmente, o capital fica em primeiro plano.

Por fim, destaca-se que "a legislação ganha qualidade quando ela dá atenção às forças e normas que, de fato, possuem eficácia na sociedade. Leis próximas da realidade podem superar direito morto por direito vivo." (MALISKA, 2015, p. 127).

Assim, o antigo entendimento de que os adicionais são inacumuláveis não mais se sustenta.

\section{CONSIDERAÇÕES FINAIS}


A visão de Eugen Ehrlich em relação ao direito vivo comprova que o dia a dia do trabalhador deve ser analisado e não apenas as leis. O princípio da primazia da realidade deve imperar nesses casos. A dominação da vida ocorre pelo direito vivo. A convivência social abordada pelo autor deve estar em contraposição ao direito vigente. $\mathrm{O}$ direito vivo é encontrado na dinâmica da vida.

A análise e a investigação do direito não deve se restringir somente as decisões judiciais, tendo em vista que não apresentam a vida jurídica de modo completo. As decisões judiciais devem ser completadas com a realidade.

O direito vivo é observado pelas partes e não apenas nas decisões judiciais. O estudo do direito vivo fornece aos futuros juristas a capacidade de verificar o mundo através dos sentidos.

O obreiro em razão de estar submetido à ambiente perigoso e insalubre, de forma simultânea, faz jus aos respectivos adicionais de forma cumulada. Os adicionais não se confundem, visto que são parcelas distintas e os fatos geradores são diversos.

Saliente-se que o fato de perceber apenas um adicional é extremamente maléfico ao obreiro. Na verdade, o correto era não haver ambiente insalubre e perigoso, mas em razão de ter, o trabalhador deve ser compensado pela exposição aos agentes.

O pagamento do adicional de insalubridade sobre o salário mínimo torna-se vantajoso ao empregador, tendo em vista que não há um grande impacto econômico. Em inúmeros locais de trabalho o empresário promete determinado salário, contudo, nessa promessa já está incluído o valor do percentual do adicional devido.

O fato de não cumular os adicionais supramencionados, desrespeita o princípio da dignidade da pessoa humana estabelecido na Carta Magna, em razão de não tornar digno o ambiente laboral.

Ressalte-se que deve prevalecer o entendimento de que o artigo $193, \S 2^{\circ}$, da CLT, foi revogado pela Convenção n. ${ }^{\circ} 155$ da OIT. A Convenção, a qual trata da segurança e saúde dos trabalhadores e meio ambiente de trabalho, é superior à CLT, visto que sua incorporação ocorreu após a referida CLT, assim, deve ser tratada como norma de caráter especial.

O princípio da norma mais favorável deve ser aplicado quando for evidenciado o conflito entre normas. No tocante à convenção internacional, não há dúvida de que essa beneficia mais o obreiro, logo, deve prevalecer e imperar em relação ao artigo 193 da CLT.

Portanto, os adicionais de insalubridade e periculosidade podem ser cumulados. 


\section{REFERÊNCIAS}

BRASIL. Decreto-lei n. ${ }^{\circ} 5.452$, de $1^{\circ}$ de maio de 1973. Aprova a Consolidação das leis do trabalho. Disponível em: <http://www.planalto.gov.br/ccivil_03/decreto-lei/Del5452.htm>. Acesso em: 17 jul. de 2016.

Tribunal Superior do Trabalho. Disponível em: <http://www.tst.jus.br/documents/guest/JURISPRUD\%C3\%8ANCIA/Informativo\%20TST/In formativo\%20TST\%20n\%C2\%BA\%20134>. Acesso em: 18 jul. de 2016.

Tribunal Regional do Trabalho da $12^{\mathrm{a}}$ Região. $1^{\mathrm{a}}$ Turma. Recurso ordinário n. $^{\mathrm{o}}$ 0002800-76.2011.5.12.0027. Relatora: Águeda Maria Lavorato Pereira. Criciúma, 6 de março de 2013. Disponível em:< http://consultas.trt12.jus.br/SAP2/DocumentoListar.do?pidDoc=218390\&plocalConexao=sap \&ptipo=PDF $>$. Acesso em: 19 ago. de 2016.

Tribunal Superior do Trabalho. $7^{\mathrm{a}}$ Turma. Recurso de Revista ${ }^{\circ}$ 7092-

95.2011.5.12.0030. Relator: Douglas Alencar Rodrigues. Disponível em: http://aplicacao4.tst.jus.br/consultaProcessual/consultaTstNumUnica.do? consulta=Consultar\& conscsjt $=\&$ numeroTst $=0007092 \&$ digitoTst $=95 \&$ anoTst $=2011 \&$ orgaoTst $=5 \&$ tribunal $\mathrm{Tst}=12$ $\&$ varaTst=0030\&submit=Consultar.> Acesso em: 07 set. de 2016.

CESÁRIO, João Humberto. Técnica processual e tutela coletiva de interesses ambientais trabalhistas. São Paulo: LTr, 2012.

COSTA, Aline Moreira da; GONÇALVES, Leandro Krebs; ALMEIDA, Victor Hugo de. Meio ambiente do trabalho e proteção jurídica do trabalhador: (Re) significando paradigmas sob a perspectiva constitucional. In: FELICIANO, Guilherme Guimarães; URIAS, João (Coords.). Direito ambiental do trabalho: apontamentos para uma teoria geral. v. 1. São Paulo: LTr, 2013.

FORMOLO, Fernando. A acumulação dos adicionais de insalubridade e periculosidade. Justiça do Trabalho, Porto Alegre, v. 23, n. 269, 2006. p. 49-64.

; SILVA, Janaína Saraiva. Cumulação de adicionais. Disponível em: <http://www.amatra4.org.br/publicacoes/cadernos/caderno-07?start=20>. Acesso em: 19 ago. 2016.

GARCIA, Gustavo Filipe Barbosa. Curso de direito do trabalho. 5. ed. São Paulo: LTr, 2005. 
GONÇALVES, Edwar Abreu. Manual de segurança e saúde no trabalho. 2. ed. São Paulo: LTr, 2003.

KROST, Oscar. Trabalho prestado em condições insalubres e perigosas: possibilidade de cumulação de adicionais. Revista Justiça do Trabalho, Porto Alegre, n. 247, 2004.

MALISKA, Marcos Augusto. Introdução à Sociologia do Direito de Eugen Ehrlich. $2^{\mathrm{a}}$ ed. Curitiba: Juruá, 2015.

MARTINS, Sérgio Pinto. Direito do trabalho. 28. ed. São Paulo: Atlas, 2012.

MELO, Raimundo Simão de. Direito ambiental do trabalho e a saúde do trabalhador. 4. ed. São Paulo: LTr, 2010.

MIRANDA, Maria Bernadete. $O$ adicional de periculosidade. Disponível em: <http://www.direitobrasil.adv.br/arquivospdf/aulas/dt/A9.pdf>. Acesso em: 20 jul. de 2016.

NASCIMENTO, Amauri Mascaro. Curso de direito do trabalho: história e teoria geral do direito do trabalho: relações individuais e coletivas do trabalho. 24. ed. rev. atual. e ampl. São Paulo: Saraiva, 2009.

OLIVEIRA, Sebastião Geraldo de. Proteção jurídica à saúde do trabalhador. 6. ed. São Paulo: LTr, 2011.

ORGANIZAÇÃO DAS NACÕES UNIDAS. Declaração de Estocolmo sobre o ambiente humano. Disponível em: <http://www.silex.com.br/leis/normas/estocolmo.htm>. Acesso em: 17 jul. de 2016.

RAMOS FILHO, Wilson. Direito capitalista do trabalho: história, mitos e perspectivas no Brasil. São Paulo: LTr, 2012.

ROCHA, Julio Cesar de Sá da. Direito ambiental do trabalho: mudança de paradigma na tutela jurídica à saúde do trabalhador. São Paulo: LTr, 2002.

RODRIGUES PINTO, José Augusto. Curso de direito individual do trabalho. 4. ed. São Paulo: LTr, 2000. 
SANTOS, Adelson Silva dos. Fundamentos do direito ambiental do trabalho. São Paulo: LTr, 2010.

SOUTO MAIOR, Jorge Luiz. Em defesa da ampliação da competência da justiça do trabalho. Disponível

em:

<http://www.jorgesoutomaior.com/uploads/5/3/9/1/53916439/em_defesa_da_amplia\%C3\%87 $\%$ C3\%83o_da_compet\%C3\%8Ancia_da_justi\%C3\%87a_do_trabalho.pdf $>$. Acesso em: 18 jul. de 2016.

VENDRAME, Antonio C. A cumulatividade dos adicionais. Revista CIPA, São Paulo, ano XVII, n. 214, 1997.

\title{
THE CUMULATIVITY OF ADDITIONAL PERICULOSITY AND NON- SUBHEADMENT BASED ON LIVE LAW
}

\begin{abstract}
The care about health should not occur only by the state but also directly by the employer in a relation of employment. Some scholars analyze only obscurely additional payment provided in the law, however, they forget the way that the exploration of workers' health happens. Does the principle of human dignity is respected when the worker at the same time is exposed to unhealthy and dangerous agents and still must choose to receive only one of the additional? In view of the workers' health is at risk to be exposed to unhealthy agent and that when it is exposed to the dangerous agent is the physical integrity of the worker who is threatened, even in this way the worker should receive only one of the additionals? According to lessons of Eugen Ehrlich, what must be analyzed is the actual activity performed by the employee on a daily basis, not just what is in the law.
\end{abstract}

Keywords: Additional of unhealthiness. Additional of dangerousness. Cumulativity of additionals. Living Law. 